\title{
Critical success factors for benchmarking implementation in oil palm industry
}

\author{
Fatimah Mahmud ${ }^{1, *}$, Baba Md Deros ${ }^{2}$, Dzuraidah Abdul Wahab ${ }^{2}$, Mohd Nizam Ab Rahman ${ }^{2}$, Rohaizan Ramlan ${ }^{3}$ \\ ${ }^{1}$ Faculty Industrial Management, Universiti Malaysia Pahang, Kuantan, Pahang, Malaysia \\ ${ }^{2}$ Faculty of Engineering and Built Environment, Universiti Kebangsaan Malaysia, Bangi, Selangor, Malaysia \\ 3Faculty of Technology Management and Business, Universiti Tun Hussein Onn, Batu Pahat, Johor, Malaysia
}

\section{A RT I C LE IN F O}

\section{Article history:}

Received 1 February 2017

Received in revised form

28 July 2017

Accepted 28 July 2017

Keywords:

Critical success factor

Benchmarking

Oil palm industry

Perception

Significance

\begin{abstract}
A B S T R A C T
This paper aims to provide the empirical evidence on the importance and practice of eight identified critical success factors (CSFs) for implementing benchmarking in oil palm industry. Prior to conducting the full survey, a pilot study and validation by benchmarking experts in this field was conducted to ensure the survey questionnaire is reliable and valid. The Cronbach alpha values for all the eight critical success factors were higher than 0.7 , which means they are reliable. To achieve this objective, 700 sets of survey questionnaire were distributed among oil palm planters and millers in Malaysia. This survey has received a good response rate of $49 \%$. On overall, the survey results had indicated that there is a significant different between actual practice of CSFs compared to their perception of importance. In the authors' opinion this survey findings would be useful and considerable interest to all level of benchmarking practitioners in the oil palm industry.
\end{abstract}

(C) 2017 The Authors. Published by IASE. This is an open access article under the CC BY-NC-ND license (http://creativecommons.org/licenses/by-nc-nd/4.0/).

\section{Introduction}

Process improvement is crucial for every organization's survival and growth. One of the most efficient ways to improve a process is to learn from the experience of others. Thus, Lee et al. (2006) beliefs that despite various sophisticated instruments engaged by the multinational companies, benchmarking as one of the simplest tool has been proven for its effectiveness to improve performance in many areas. Benchmarking makes it easy to identify the gap between where the organization would like to be, where it actually is now and this gap provides a measure of the improvement an organization would like to make (Magd and Curry, 2003). Nevertheless, Chin et al. (2008) have shown that many benchmarking implementation efforts have failed because the critical success factors were not correctly determined and put in-placed. Even though there has been a large number of articles published related to benchmarking in the last few decades, only very few articles focused on documenting the CSFs of benchmarking.

\footnotetext{
* Corresponding Author.

Email Address: fatimahm@ump.edu.my (F. Mahmud) https://doi.org/10.21833/ijaas.2017.09.017

2313-626X/C 2017 The Authors. Published by IASE.

This is an open access article under the CC BY-NC-ND license

(http://creativecommons.org/licenses/by-nc-nd/4.0/)
}

Therefore, this paper aims to identify the CSFs of benchmarking and provide the empirical evidence on the importance and practice of each CSFs for implementing benchmarking in the oil palm industry. This paper will be structured as follows: first, the review of critical success factor in past studies from different industries. It is followed by describing the methodology used in this research. The final section presents an analysis on the perception of level of importance and extent of practices of the CSFs in oil palm industry. Several significant tests were performed to investigate the existence of differences between the level of importance and practice and the relationship among CSFs. These analyses were conducted for both; oil palm plantation and palm oil mill. Finally, the paper culminates with the general conclusions from the survey together with some recommendations to improve any of the attributes on the CSFs adoption.

\section{Literature review on critical success factor}

CSFs are those which are essential to the success of any program or technique, in the sense that, if objectives associated with the factors are not achieved, the process stands a good chance of ending in failure (Rungasamy et al. 2002; Thiagarajan and Zairi, 1998).

According to Fryer et al. (2007), it is important to define the CSFs for benchmarking implementation in 
order to increase the success rate, reduce costs and prevent disillusionment with continuous improvement programs. Meanwhile, Dobbins and Donelly (1998) defined the CSFs as "key areas; where things must go right for the business to flourish. If results in these areas are not adequate, the organization's efforts for the period will be less than desired". Therefore, these CSFs must be constantly monitored, maintained and improved to ensure successful performance by the organization (Guimaraes and Langley, 1994). Gadenne and Sharma (2009) classified the CSFs into two groups; 'soft' factors and 'hard' factors. The 'soft' factors are more concerned on behavioral aspects and, tool and systems aspects are more related to 'hard' factors. Both soft and hard factors complement each other.

Through a comprehensive literature review, the authors have identified eight critical success factors with 54 attributes that believed to be critical for benchmarking implementation. The CSFs encompass of Top Management and Leadership, Human Resources Management, Employee Satisfaction Management, Policy and Strategic Planning, Employee Participation, Customer Satisfaction Management, Process and Innovation Management and Business Performance. Table 1 shows the general description of each identified CSFs.

There are many different researchers that have attempted to investigate the CSFs in benchmarking implementation which covered in different field of study and industries as summarized in Table 2 . Guven-Uslu (2005) had identified a set of CSFs extracted from two frameworks. The first framework was from the receptive contexts of change model and the second was from the EFQM Business Excellence Model. He classified the CSFs into three categories namely, external factors, organizational factors and individual factor of benchmarking implementation.

Table 1: Description of critical success factors

\begin{tabular}{|c|c|c|}
\hline & CSFs & Description \\
\hline F1 & $\begin{array}{c}\text { Top Management } \\
\text { Commitment and Leadership }\end{array}$ & $\begin{array}{l}\text { How the behavior and actions of the executive team and all other leaders inspire, support and promote } \\
\text { a culture of business excellence as the best way to achieve the organization's objectives }\end{array}$ \\
\hline $\mathrm{F} 2$ & $\begin{array}{l}\text { Human Resources } \\
\text { Management }\end{array}$ & $\begin{array}{l}\text { How the organization manages its resources (financial resources, information resources, technological } \\
\text { resources, material resources and fixed assets within the organization) effectively and efficiently }\end{array}$ \\
\hline F3 & $\begin{array}{l}\text { Employee Satisfaction } \\
\text { Management }\end{array}$ & What the organization is achieving in relation to the satisfaction of its employees \\
\hline F4 & Policy and Strategic Planning & How the organization formulates, deploys, reviews, turns policy and strategy into plans and actions \\
\hline F5 & Employee Participation & How the organization releases the full potential of its people \\
\hline F6 & $\begin{array}{l}\text { Customer Satisfaction } \\
\text { Management }\end{array}$ & What the organization is achieving in relation to the satisfaction of its external customers \\
\hline F7 & $\begin{array}{l}\text { Process and Innovation } \\
\text { Management }\end{array}$ & How the organization identifies, manages, reviews and improves its processes \\
\hline F8 & Business Performance & $\begin{array}{l}\text { What the organization is achieving in relation to its planned objectives and in satisfying the needs and } \\
\text { expectations of everyone with an interest or other stake in the organization }\end{array}$ \\
\hline
\end{tabular}

Table 2: Critical success factors of benchmarking

\begin{tabular}{|c|c|c|c|c|c|c|c|c|c|}
\hline \multirow{2}{*}{ Researcher } & \multirow{2}{*}{ Type of industry } & \multicolumn{8}{|c|}{ Critical success factor } \\
\hline & & F1 & F2 & F3 & $\mathrm{F} 4$ & F5 & F6 & F7 & F8 \\
\hline Guven-Uslu (2005) & Health & $\mathrm{X}$ & & & $\mathrm{X}$ & $\mathrm{X}$ & & & \\
\hline Hwang and Lockwood (2006) & Tourism & & $\mathrm{X}$ & $\mathrm{X}$ & & & $\mathrm{X}$ & & \\
\hline Kyriakidou and Gore (2005) & Tourism & & & $\mathrm{X}$ & & $\mathrm{X}$ & $\mathrm{X}$ & & \\
\hline Sohal and Terziovski (2000) & Manufacturing & $\mathrm{X}$ & & $\mathrm{X}$ & $\mathrm{X}$ & $\mathrm{X}$ & $\mathrm{X}$ & & \\
\hline Mohamed (1996) & Construction & $\mathrm{X}$ & $\mathrm{X}$ & & & $\mathrm{X}$ & & $\mathrm{X}$ & \\
\hline Brah et al. (2000) & $\begin{array}{c}\text { Manufacturing and } \\
\text { service }\end{array}$ & $\mathrm{X}$ & $\mathrm{X}$ & & & $\mathrm{X}$ & & & \\
\hline Fuller (2000) & Health and safety & & & & & & & $\mathrm{X}$ & $\mathrm{X}$ \\
\hline Meybodi (2009) & Manufacturing & & $\mathrm{X}$ & $\mathrm{X}$ & $\mathrm{X}$ & $\mathrm{X}$ & $\mathrm{X}$ & & $\mathrm{X}$ \\
\hline Kowalski and Swanson (2006) & Communication & $\mathrm{X}$ & & $\mathrm{X}$ & & $\mathrm{X}$ & & $\mathrm{X}$ & \\
\hline
\end{tabular}

From in-depth interviews conducted with owners, managers and staff in 89 award-winning business in the hospitality and tourism industry, Hwang and Lockwood (2006) identified seven CSFs associated with benchmarking implementation success, namely; customer focused goals, planning and control, partnering and networking, internal and external communication, achieving consistent standards, strategic workforce management, cash flow and performance management. Hwang and Lockwood (2006) strongly stressed that the emphasis could move away from copying competitors and gaining competitive advantage through distinctive performance, to rather motivating and allowing experience sharing in networks regarding mutual problems for future excellence.
Based on a survey conducted by Sohal and Terziovski (2000) among 895 manufacturing companies in Australia, they discovered that positive attitude towards quality improvement, leadership education and training, integrating the voice of the customer and the supplier, developing appropriate performance indicators and rewards are the most critical factors to the TQM implementation success. In addition, the needs and culture of the organization must be developed and supported at all levels with adequate training and education must be imparted. In order to investigate the state of benchmarking in the manufacturing and service sectors of Singapore, Brah et al. (2000) had examined the factors that affect the implementation of a benchmarking process. They identified top level management support, employee participant, internal self- 
assessment and self-benchmarking process as the preconditions or the critical factors before the companies can start a benchmarking program. Conversely, lack of consideration of the above CSFs will lead to the failure in the organization benchmarking effort.

Value management (VM) is a powerful technique to increase the value of a product or services by reducing its production or other costs. Based on study conducted by Fong et al. (2001), there is several critical factors of benchmarking VM success were identified. They are management commitment, group effectiveness, customer satisfaction, brainstorming and project team formation. Kowalski and Swanson (2006) main objective was to provide a framework of critical success factors for practitioners and employers looking to develop new or enhance existing telework programs. These critical success factors include support, communication, and trust. They are interrelated and should be applied at multiple levels including organizational, managerial, and employee levels. The researchers emphasize on the role of top management in creating the culture of trust, facilitate the good communication and provide sufficient training to all level of employees.

Table 2 also revealed the deficiency in some of CSFs identification research. For example, Sohal and Terziovski (2000) did not consider human resource management, process and innovation management and business performance. Meanwhile, Fuller (2000) only concerned on two CSFs (i.e. process and innovation management and business performance). Clearly, not even one researcher had considered the wholesome of CSFs as identified in this paper. Therefore, the needs to discover and overcome these deficiencies are very important in ensuring the success of benchmarking implementation. In addition, there is no specific literature that conducted a review on benchmarking CSFs in the oil palm industry. However, through a comprehensive literature review, identification was done by looking at CSFs of previous benchmarking studies involving a variety of areas and types of industry.

\section{Research methodology}

\subsection{Survey instrument}

The methodology adopted in this research is a self-administered questionnaire with pilot tests and validation by benchmarking experts (i.e. benchmarking practitioners and academicians) before being distributed to the respondents. A pilot study was conducted by visiting a few of oil palm plantations and mills. Based on the results and comments from the pilot tests and validations, revisions were made to the questionnaire design and contents.

The final survey instrument was distributed via postal mail to 350 palm oil mill managers and 350 oil palm plantation managers in Malaysia. The respondents were asked to rate the level of perception on the importance and the extent of actual practices on each of benchmarking CSFs in their organization. For the perceived importance, the rating scale ranged from $0=$ don't know/unsure, $1=$ not important at all, $2=$ not important, $3=$ neutral, 4 = important and $5=$ very important. Meanwhile for actual CSFs adoption and practice in their organization, the rating scale used were from $0=$ don't know/unsure, 1 = very low, 2 = low, 3 = moderate, $4=$ high to $5=$ very high.

In addition, the instrument was examined using Cronbach alpha to test the consistency of each item to be assessed in the questionnaires as tabulated in Table 3. All factors in the survey instrument have Cronbach alpha values of more than 0.70 , which indicates the instrument is reliable (Coakes et al., 2006). In order to ensure high response rate, support letters for the survey were obtained from Malaysian Palm Oil Board (MPOB) and top management of several palm oil companies. These support letters were attached together with the survey instrument during distribution to the respondents. As a result, a total of 343 companies (i.e. 163 from oil palm plantations and 180 from palm oil mills) responded to the questionnaire giving a response rate of about $49 \%$.

\subsection{Hypotheses}

The following formal hypotheses were formulated based on the respondent perception on the importance and practice of CSFs from the survey. All statistical analyses in this paper were performed by using a statistical software package SPSS 22.0 for Windows.

H1. There is no significant difference between the means of the importance and practice of CSFs in oil palm plantations.

H2. There is no significant difference between the means of the importance and practice CSFs in palm oil mills.

\section{Findings and analysis}

\subsection{Respondents' demographic background}

All respondents were assumed to have a broad knowledge and well-experienced with respect to the firm's operational and practices because majority of them have more than ten years' working experience in the oil palm industry. Approximately $47 \%$ of the respondents had obtained some form of quality certification, while the remaining $53 \%$ were not certified to any quality certification system.

\subsection{Importance and practice of CSFs in oil palm plantations and palm oil mills}

The main purpose of this section is to discover the perception on the importance and the extent of practice of eight benchmarking CSFs in oil palm 
plantations and palm oil mills. The analysis was conducted using Paired comparison t-test to test the existence of the significance difference between importance and practice of CSFs.

From Table 4 and Table 5, it appears that, there were significance differences in mean values for all success factors and generates the p-values of less than 0.05 for oil palm plantations and palm oil mills; hence the Hypothesis 1 and Hypothesis 2 were rejected. For both, plantations and mills perceived that the three most critical factors that must be considered to ensure the success of benchmarking implementation are Customer Satisfaction Management, Process and Innovation Management and Top Management Commitment and Leadership.

Meanwhile, Employee Satisfaction Management and Policy and Strategic Planning become the two least factors practicing factors. However, the respondents may have full awareness on all critical success factors of benchmarking implementation but they failed to fully practice it in their organization. For both; oil palm plantation and palm oil mill, there is large difference in mean value of the importance and actual practice appears for Top Management Involvement and Leadership and Employee Participation benchmarking CSFs.

Lack of readiness of top management to harmonize the benchmarking in organization's policy and strategic planning may lead to existence of this gap.

The desires to learn, openness, build a sense of urgency and awareness to adopt new initiatives must come from top management. As stated by Seetharaman et al. (2006), with a clear line of responsibility and command running up to an accountable individual at the top of the management and reviewing quality improvement is another method of showing management commitment.

Table 3: CSFs reliability test

\begin{tabular}{|c|c|c|c|}
\hline & Benchmarking CSFs & No. of item & $(\alpha)$ Value \\
\hline F1 & Top Management and Leadership & 8 & 0.953 \\
\hline $\mathrm{F} 2$ & Human Resources Management & 6 & 0.938 \\
\hline F3 & Employee Satisfaction Management & 7 & 0.968 \\
\hline $\mathrm{F} 4$ & Policy and Strategic Planning & 8 & 0.956 \\
\hline F5 & Employee Participation & 7 & 0.950 \\
\hline F6 & Customer Satisfaction Management & 5 & 0.928 \\
\hline F7 & Process and Innovation Management & 5 & 0.944 \\
\hline F8 & Business Performance & 7 & 0.960 \\
\hline
\end{tabular}

Table 4: Paired Sample t- test for Mean importance and practice for oil palm plantations

\begin{tabular}{|c|c|c|c|c|c|}
\hline \multirow{2}{*}{ CSFs } & \multirow{2}{*}{ NO. OF ITEMS } & \multicolumn{4}{|c|}{ OIL PALM PLANTATION } \\
\hline & & Importance (mean) & Practice (mean) & Diff. in mean & p-value \\
\hline $\begin{array}{l}\text { F1 : Top management Commitment and } \\
\text { Leadership }\end{array}$ & 8 & 4.28 & 3.77 & 0.515 & $* 0.000$ \\
\hline F2 : Human Resources Management & 6 & 4.02 & 3.90 & 0.375 & $* 0.000$ \\
\hline F3 : Employee Satisfaction Management & 7 & 3.95 & 3.48 & 0.474 & $* 0.000$ \\
\hline F4 : Policy \& Strategic planning & 8 & 4.17 & 3.66 & 0.513 & $* 0.000$ \\
\hline F5 : Employee Participation & 7 & 4.21 & 3.70 & 0.510 & $* 0.000$ \\
\hline F6 : Customer Satisfaction Management & 5 & 4.32 & 3.86 & 0.456 & $* 0.000$ \\
\hline F7 : Process and Innovation Management & 6 & 4.29 & 3.92 & 0.375 & $* 0.000$ \\
\hline F8 : Business Performance & 7 & 4.24 & 4.01 & 0.231 & $* 0.000$ \\
\hline
\end{tabular}

Table 5: Paired Sample t- test for Mean importance and practice for palm oil mill

\begin{tabular}{|c|c|c|c|c|c|}
\hline \multirow[b]{2}{*}{ CSFs } & \multirow{2}{*}{$\begin{array}{l}\text { NO. OF } \\
\text { ITEMS }\end{array}$} & \multicolumn{4}{|c|}{ PALM OIL MILL } \\
\hline & & $\begin{array}{l}\text { Importance } \\
\text { (mean) }\end{array}$ & $\begin{array}{l}\text { Practice } \\
\text { (mean) }\end{array}$ & Diff. in mean & p-value \\
\hline F1 : Top management Commitment \& Leadership & 8 & 4.14 & 3.51 & 0.635 & $* 0.000$ \\
\hline F2 : Human Resources Management & 6 & 3.84 & 3.23 & 0.607 & $* 0.000$ \\
\hline F3 : Employee Satisfaction Management & 7 & 3.86 & 3.15 & 0.711 & $* 0.000$ \\
\hline F4 : Policy and Strategic planning & 8 & 3.96 & 3.34 & 0.626 & $* 0.000$ \\
\hline F5 : Employee Participation & 7 & 3.98 & 3.29 & 0.691 & $* 0.000$ \\
\hline F6 : Customer Satisfaction Management & 5 & 4.15 & 3.70 & 0.450 & $* 0.000$ \\
\hline F7 : Process and Innovation Management & 6 & 4.02 & 3.44 & 0.578 & $* 0.000$ \\
\hline F8: Business Performance & 7 & 4.02 & 3.59 & 0.433 & $* 0.000$ \\
\hline
\end{tabular}

In the meantime, the absence of readiness to change or the change occurs rapidly may create the anxiety to the employees to fully participate in benchmarking implementation (Mahmud et al., 2012).

Findings also show that there is a need to emphasize and fully practice in balance of all eight CSFs in order to increase the success rate of benchmarking adoption in oil palm industry. For instance, the critical factors that need to be given attention in oil palm plantation and palm oil mill are the Policy and Strategic Planning, Employee Participation and Customer Satisfaction Management. By incorporating benchmarking in strategic planning process and clearly apprise the employee on organization vision and mission will increase their readiness to participate and institutionalize benchmarking implementation. Subsequently, this will lead to the enhancement of customer satisfaction management and increase the customer loyalty. 


\section{Conclusion}

From the analyses, it is clearly seen that organization which desired to successfully implement benchmarking shall aware and practice the CSFs which had been identified in this paper. The authors strongly believed that this finding may be able to provide the richness of knowledge and guidance to oil palm managers and policy makers for implementing benchmarking. Since the survey was conducted and the analysis was performed separately between oil palm plantation and palm oil mill. This is in relation to the need to produce high quality and high rate of oil extraction from the mills relatively important for the oil palm plantation to produce high yield and high quality of fresh fruit bunch (FFB). This paper revealed that there is significance difference on the importance and actual practice of identified benchmarking CSFs in oil palm plantation and palm oil mill. By incorporating these findings in the benchmarking implementation process, it will help the benchmarking practitioners in oil palm industry to obtain full benefits from the benchmarking initiative and avoid failure during implementation. Future research could scrutinize the impact of the benchmarking CSFs practices towards company ownership and quality certified company.

\section{References}

Brah SA, Ong AL, and Rao BM (2000). Understanding the benchmarking process in Singapore. International Journal of Quality and Reliability Management, 17(3): 259-275.

Chin KS, Chan BL, and Lam PK (2008). Identifying and prioritizing critical success factors for coopetition strategy. Industrial Management and Data Systems, 108(4): 437-454.

Coakes SJ, Steed L, and Dzidic P (2006). SPSS version 13.0 for Windows: Analysis without anguish. John Wiley and Sons Australia Ltd, Queensland, Australia.

Dobbins JH and Donelly RG (1998). Summary research report on critical success factors in federal government program management. Acquisition Review Quarterly, 61-81. Available online at: http://www.dtic.mil/docs/citations/ADA487780

Fong PSW, Shen Q, and Cheng EWL (2001). A framework for benchmarking the value management process. Benchmarking: An International Journal, 8(4): 306-316.

Fryer KJ, Antony J, and Douglas A (2007). Critical success factors of continuous improvement in public sector: A literature review and some key findings. The TQM Magazine, 19(5): 497517.
Fuller C (2000). Modelling continuous improvement and benchmarking processes through the use of benefit curves. Benchmarking: An International Journal, 7(1): 35-51.

Gadenne D and Sharma B (2009). An investigation of the hard and soft quality management factors of Australian SMEs and their association with firm performance. International Journal of Quality and Reliability Management, 26(9): 865-880.

Guimaraes T and Langley K (1994). Developing innovation benchmarks: an empirical study. Benchmarking for Quality Management and Technology, 1(3): 3-20.

Guven-Uslu P (2005). Benchmarking in health services. Benchmarking: An International Journal, 12(4): 293-309.

Hwang LJJ and Lockwood A (2006). Understanding the challenges of implementing best practices in hospitality and tourism SMEs. Benchmarking: An International Journal, 13(3): 337354.

Kowalski KB and Swanson JA (2006). Critical success factors in developing teleworking programs. Benchmarking: An International Journal, 12(3): 236-249.

Kyriakidou 0 and Gore J (2005). Learning by example: Benchmarking organizational culture in hospitality, tourism and leisure SMEs. Benchmarking: An International Journal, 12(3): 192-206.

Lee YP, Zailani S, and Soh KL (2006). Understanding factors for benchmarking adoption: New evidence from Malaysia. Benchmarking: An International Journal, 13(5): 548-565.

Magd H and Curry A (2003). Benchmarking: Achieving best value in public-sector organisations. Benchmarking: An International Journal, 10(3): 261-286.

Mahmud F, Deros BM, Wahab DA, and Rahman MNA (2012). A Survey on The Barrier of Benchmarking in Malaysia oil palm industry. Jurnal Teknologi, 59(2): 47-54.

Meybodi MZ (2009). Benchmarking performance measures in traditional and just-in-time companies. Benchmarking: An International Journal, 16(1): 88-102.

Mohamed S (1996). Benchmarking and improving construction productivity. Benchmarking for Quality Management and Technology, 3(3): 50-58.

Rungasamy S, Antony F, and Ghosh S (2002). Critical success factors for SPC implementation in UK small and medium enterprises: Some key findings from a survey. The TQM Magazine, 14(4): 217-224.

Seetharaman A, Sreenivasan J, and Boon LP (2006). Critical success factors of total quality management. Quality and Quantity, 40(5): 675-695.

Sohal AS and Terziovski M (2000). TQM in australian manufacturing: Factors critical to success. International Journal of Quality and Reliability Management, 17(2): 158167.

Thiagarajan T and Zairi M (1998). An empirical analysis of critical factors of TQM. Benchmarking for Quality Management and Technology, 5(4): 291-303. 